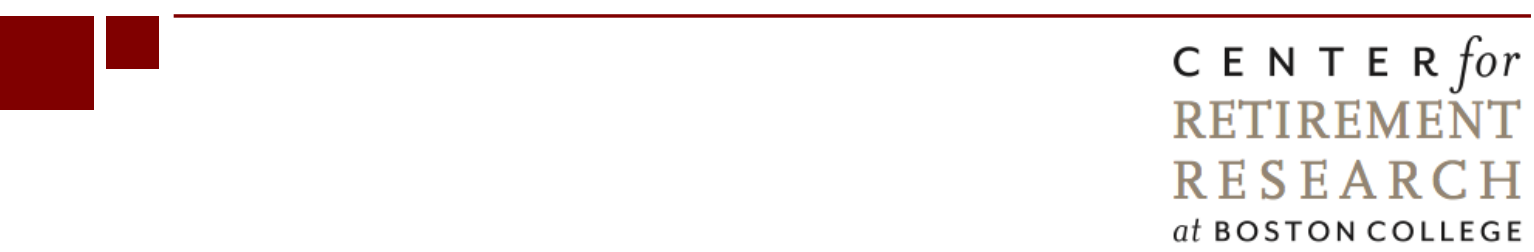

\title{
THE ECONOMIC BURDEN OF OUT-OF-POCKET MEDICAL EXPENDITURES BEFORE AND AFTER IMPLEMENTATION OF THE MEDICARE PRESCRIPTION DRUG PROGRAM
}

\author{
Ayse Akincigil and Karen Zurlo \\ CRR WP 2015-28 \\ November 2015 \\ Center for Retirement Research at Boston College \\ Hovey House \\ 140 Commonwealth Avenue \\ Chestnut Hill, MA 02467 \\ Tel: 617-552-1762 Fax: 617-552-0191 \\ http://crr.bc.edu
}

Ayse Akincigil is an associate professor and Karen Zurlo is an assistant professor at Rutgers, The State University of New Jersey. The research reported herein was performed pursuant to a grant from the U.S. Social Security Administration (SSA) funded as part of the Retirement Research Consortium. The opinions and conclusions expressed are solely those of the authors and do not represent the opinions or policy of SSA, any agency of the federal government, Rutgers, The State University of New Jersey, or Boston College. Neither the United States Government nor any agency thereof, nor any of their employees, makes any warranty, express or implied, or assumes any legal liability or responsibility for the accuracy, completeness, or usefulness of the contents of this report. Reference herein to any specific commercial product, process or service by trade name, trademark, manufacturer, or otherwise does not necessarily constitute or imply endorsement, recommendation or favoring by the United States Government or any agency thereof.

(C) 2015, Ayse Akincigil and Karen Zurlo. All rights reserved. Short sections of text, not to exceed two paragraphs, may be quoted without explicit permission provided that full credit, including (C) notice, is given to the source. 


\section{About the Steven H. Sandell Grant Program}

This paper received funding from the Steven H. Sandell Grant Program for Junior Scholars in Retirement Research. Established in 1999, the Sandell program's purpose is to promote research on retirement issues by scholars in a wide variety of disciplines, including actuarial science, demography, economics, finance, gerontology, political science, psychology, public administration, public policy, sociology, social work, and statistics. The program is funded through a grant from the Social Security Administration (SSA). For more information on the Sandell program, please visit our website at: http://crr.bc.edu/?p=9570, send e-mail to crr@bc.edu, or call (617) 552-1762.

\section{About the Center for Retirement Research}

The Center for Retirement Research at Boston College, part of a consortium that includes parallel centers at the University of Michigan and the National Bureau of Economic Research, was established in 1998 through a grant from the Social Security Administration. The Center's mission is to produce first-class research and forge a strong link between the academic community and decision-makers in the public and private sectors around an issue of critical importance to the nation's future. To achieve this mission, the Center sponsors a wide variety of research projects, transmits new findings to a broad audience, trains new scholars, and broadens access to valuable data sources.

Center for Retirement Research at Boston College

Hovey House

140 Commonwealth Ave

Chestnut Hill, MA 02467

Tel: 617-552-1762 Fax: 617-552-0191

http://crr.bc.edu

Affiliated Institutions:

The Brookings Institution

Massachusetts Institute of Technology

Syracuse University

Urban Institute 


\begin{abstract}
Older Americans, although covered by Medicare, bear a large economic burden of medical expenses in the form of premiums for Medicare and supplemental plans, as well as the cost of uncovered or under-covered medical services. This study compares the patterns of this economic burden in 2010 with the baseline year of 2005. The period covered was marked by economic shocks, health care technology innovations and major Medicare reforms, including implementation of the prescription drug (Part D) program and changes in premium rules. Consequently, we present a description of the economic burden and do not attempt to make causal inferences. The definition of expenditures is limited to three components of out-of-pocket (OOP) medical spending: premiums, prescription drugs costs, and health services. While this definition is a limitation of the study, it also allows the researchers to focus on the costs most likely to be affected by improved access to prescription drugs and premium reforms.
\end{abstract}

This paper found that:

- Overall, the economic burden (expressed as a percent of income spent on OOP expenditures and premiums) averaged 18.5 percent of 2010 income, with top decile spending at 32 percent or more of their income going to health care.

- A typical beneficiary spent 1.4 percentage points less of their income in 2010 than in 2005. When this burden is decomposed, we observed that the share of income spent for prescription drugs declined by 1.3 percentage points. This was the major component of the decline in this burden. The burden of premiums increased over the period, offsetting some of the gains from declining expenses for prescription drugs.

- These gains were mostly observed at the high end of the burden distribution, i.e., those who were spending more than 20 percent of their income on health care. This group had lower incomes, on average, and were much less likely to possess employersponsored supplemental (or self-purchased) coverage.

- Dual eligibles experienced a lower economic burden in 2010, even though their incomes were also significantly lower compared to the rest of the Medicare beneficiaries. Compared to other Medicare beneficiaries, they experienced relatively larger reductions in economic burden between 2005 and 2010. 
The policy implications of this paper are:

- We observed some relief in the economic burden of prescription drug expenditures and overall health care, particularly for those who were most vulnerable to financial strains.

- Our observations were consistent with the intended direction of policies implemented during the period. However, one can argue that the size of the gains was unremarkable when compared to the scope of the Part D reform.

- Medicaid continued to fulfill its role as a safety net for those who are most vulnerable to financial strains. The relatively higher rate of decline for duals or low-income beneficiaries suggests that key components of the reform (premium- and cost-sharing assistance) are reaching the intended targets.

- Affordability of high-cost drugs for the management of chronic conditions continues to be a major national health policy challenge. Medicare policy changes are likely to continue affecting out-of-pocket cost exposure to medications, particularly with the introduction and expansion in use of very high-priced specialty medications. Given the size and the unequal distribution of the economic burden of health care, we conclude that the economic burden needs to be a continuous concern when policy alternatives are discussed. 


\section{Introduction}

Health care is a major line item in the budgets of the elderly population of the United States and a significant determinant of their financial security. Medicare offers health insurance coverage for 95 percent of Americans ages 65 or older, providing substantial financial protection. Although Medicare provides coverage for inpatient services without additional premium costs, ${ }^{\text {a }}$ to obtain coverage for most outpatient medical services and therapeutics, ${ }^{b}$ beneficiaries must pay a premium, which constitutes a major portion of health care spending. In addition, the elderly’s health care costs are not limited to Medicare premiums. Traditional Medicare covers only a portion of medical expenditures; cost-sharing policies (e.g., deductibles, copayments) and uncovered health services result in a significant amount of out-of-pocket medical expenses. A large percentage of older adults have a variety of supplemental insurance policies that reduce such expenses-but the premiums for those plans increase the cost of health care. Even those who supplement their coverage incur significant out-of-pocket expenses (Crystal, Johnson, and Harman 2000; Goldman and Zissimopoulos 2003; Neuman, Cubaniski, Desmond, et al. 2007; Neuman, Cubanski, and Damico 2009; Zissimopoulos, Joyce, Scarpati, et al. 2015; and Desmond, Rice, Cubanski, et al. 2007).

The economic burden of health care is conceptualized as the share of beneficiaries' income spent on out-of-pocket expenses (premiums, deductibles, copayments, spending for uncovered medical expenses). It is not distributed uniformly among the U.S. elderly, because of variations in income, premiums (for Medicare as well as supplemental plans), and the cost of uncovered or under-covered services. Individuals with low incomes are at high risk for bearing a large economic burden; income not only factors into the denominator of the economic burden definition, but it also determines the affordability of supplemental insurance coverage for the beneficiary, resulting in lower coverage rates and high out-of-pocket spending for health services. Premiums for the basic Medicare plan are important public policy tools, and the government subsidizes them based on the beneficiary’s income. Medicare beneficiaries can obtain supplemental coverage through a variety of mechanisms (e.g., entitlement to Medicaid; receiving benefits from former employers; or participating in the insurance market place by

\footnotetext{
${ }^{a}$ Known as Medicare Part A. Some elderly people pay the Part A premium, because neither they nor their spouses have sufficient work history to qualify for free coverage.

${ }^{\mathrm{b}}$ Medicare Part B coverage.
} 
joining capitation plans ${ }^{\mathrm{a}}$ rather than traditional Medicare, which is a fee-for-service plan, or remaining in the traditional plan but purchasing additional supplemental coverage ${ }^{\mathrm{b}}$ ). The premiums and benefits of supplemental policies vary widely not only between these mechanisms but also within them, including major geographic area variations. For example, the national average premium for Medigap Plan F in 2010 was \$1,479, whereas in Connecticut the average premium was $\$ 2,493$, and Indiana had the highest premium variation with one plan having a premium of \$14,604 (Fronstin, Salisbury, and VanDerhei 2012). All of these factors result in dramatic variation in out-of-pocket costs. Another major source of variation in the burden of health care for the elderly is their vastly different health care needs. Consequently, beneficiaries bear a tremendous variation in burden of health care costs.

Prior to the implementation of Part D, a major source of economic burden was prescription drugs, particularly for those who did not have supplemental coverage (Crystal, Johnson, and Harman 2000; Goldman and Zissimopoulos 2003; and Shea, Stuart, and Briesacher 2003), since traditional Medicare did not cover prescription drugs, although some enrollees had comprehensive prescription drug coverage before the implementation. The reform in 2006 made coverage available to beneficiaries at a certain premium, with substantial premium and costsharing assistance for beneficiaries with low incomes. Enrollment in Medicare drug plans is voluntary, with the exception of beneficiaries who are dually eligible for both Medicare and Medicaid and certain other low-income beneficiaries who are automatically enrolled in a prescription drug plan if they do not choose a plan on their own (The Henry J. Kaiser Family Foundation 2014).

The introduction of Medicare Part D was associated with a meaningful increase in the use of selected essential medications (Schneeweiss, Patrick, Pedan, et al. 2009). The effects of Part D have been studied extensively, examining outcomes including use of prescription drugs, pharmaceutical prices, utilization of health services, health status, disparities, medication adherence for chronic conditions, and cost-related medication non-adherence, but the not economic burden of health care (Schneeweiss, Patrick, Pedan, et al. 2009; Zhang, Yin, Sun, et al. 2008; Kaestner and Khan 2010; Duggan and Morton 2008; Zhang, Donohue, Lave, et al. 2009; and Ingber, Freman, Healy, et al. 2011). The objective of the current report is to describe the

\footnotetext{
${ }^{\text {a }}$ Marketed as Medicare Advantage Plans to the consumers.

${ }^{\mathrm{b}}$ Marketed as Medigap policies to the consumers.
} 
economic burden of out-of-pocket medical expenditures experienced by older, communitydwelling elderly, five years after the implementation of the prescription drug benefit program, and compare it to the year before its implementation (2005) by providing results using nationally representative data from the Medicare Current Beneficiary Survey (MCBS). In particular, we are focusing on three components of out-of-pocket spending that could be directly affected by a major change in prescription drug coverage: premiums, spending on prescription drugs, and spending on health services that are likely to be affected by improved access to prescription drugs (i.e., inpatient and outpatient services), as suggested by existing literature (Trivedi, Moloo, and Mor 2010).

Many of the underinsured adults, that is, adults who have high out-of-pocket costs or deductibles relative to their incomes, reported problems with medical bills or had accumulated medical debt, resulting in lingering financial problems, such as using up all their savings for medical bills. They also were forgoing needed health care, such as not going to the doctor when sick; not filling a prescription; skipping a test, dose of medication or other treatment recommended by a doctor; or not seeing a specialist because of the economic burden they faced (Collins, Rasmussen, Beutel, and Doty 2015). Medical debt is increasing, and a greater number of older Americans are filing for bankruptcy (Pottow 2011). Debates over the sustainability of Medicare have been a constant feature of American political life. Shifting costs back to beneficiaries will continue to be a major policy tool to achieve sustainability. An improved understanding of the economic burden of health care for Medicare beneficiaries is vital to inform policy development choices at a time when numerous cost containment proposals that could shift costs to beneficiaries are under consideration.

\section{Methods}

The study analyzes data from the MCBS, an ongoing ${ }^{\mathrm{a}}$ survey of a nationally representative sample of Medicare beneficiaries conducted by Center for Medicare and Medicaid Services every year. It is a multipurpose survey; one of its central goals is to determine expenditures for all of the health services used by Medicare beneficiaries. Therefore, the service use data are not limited to expenditures paid by Medicare but also include non-covered services. Another goal of the survey is to capture all sources of payment for health services, including co-

\footnotetext{
${ }^{\mathrm{a}}$ Data have been collected since 1991.
} 
payments and deductibles. Along with its external validity, these features make MCBS the ideal source of data to capture out-of-pocket expenditures for medical care.

In order to be representative of Medicare beneficiaries in each year, MCBS uses a fouryear rotating panel design. Sampled subjects remain in the panel for no more than four years, at which time they are retired and replaced by newly sampled subjects. Consequently, the subjects interviewed in 2010 were not interviewed in 2005. In other words, the sample of the current report, the pooled data from 2005 and 2010 are repeated cross-sections.

There were 10,471 unique beneficiaries in the 2010 MCBS. $^{\text {a }}$ The focus of the current study are community-dwelling elderly; therefore, the sample was limited to beneficiaries who were in the community for 365 days $(n=8,939)$, of which 1,546 were younger than age 65 and excluded from the study sample. Beneficiaries who were not enrolled in Medicare Part A and Part B during the entire year (according to Medicare administrative records) were also excluded $(n=350)$. Of the remaining beneficiaries, 11 were further excluded because their income data were missing, and income contributes to the definition of the dependent variables in the study. Final sample size for year 2010 was 7,032 beneficiaries. This number corresponds to a national estimate of 32 million beneficiaries. The same criteria were applied to data from year 2005, yielding a sample size of 7,936, corresponding to a national estimate of 29 million beneficiaries. See supplemental table 1 for details.

\section{Measures}

Administrative records were used to determine beneficiaries’ sex, age, and race/ethnicity. Survey reports were used to determine education, income, marital status, and self-reported health. The self-rated health question was, "In general, compared to other people your age, would you say that your health is...” with a five-level response format, ranging from excellent to poor. The annual income measure in the MCBS comprises multiple sources of income including employment, pensions, savings, rental property, annuities, investments, business activities, and public assistance. For married respondents, income is measured for the couple and not for the individual.

Economic burden (of health care in general, and of premiums, health services, or prescription drugs in particular) is defined as out-of-pocket spending as a share of income. The

\footnotetext{
${ }^{\mathrm{a}}$ In Cost and Use files, which represents the ever-enrolled population for a given year.
} 
manner in which income is measured in the MCBS generates a challenge for burden calculations because income is the denominator of the economic-burden constructs. To treat economic resources comparably across married and single beneficiaries, income for married was adjusted by multiplying it with an index derived from poverty thresholds for a single person, divided by the poverty threshold for a household of two in that year. The thresholds were specific for those age 65 (U.S. Census Bureau 2015). This approach presumes that the entire family income, in excess of the amount necessary to secure an adequate but modest living, is considered an individual resource that can be spent on health care.

Out-of-pocket spending on health care is divided into (1) premiums; (2) out-of-pocket spending for health care services (coinsurance and deductibles); and (3) out-of-pocket spending for prescription drugs. Premiums include Medicare parts A, B, and D premiums and/or premiums paid for supplemental insurance plans. Health care services include events recorded as inpatient stays or outpatient ambulatory care and exclude spending for institutional care (those who did not reside in the community for the entire year were excluded from the sample), home health care, dental, or hospice, which are beyond the focus of the current paper. Health service and prescription drug events include both administrative and self-reported services. MCBS data are published with annual service- and payer-specific summaries, reconciling the spending for the medical events, which we used rather than making our own reconciliation. The outliers for the expenditures were cleaned by first taking the log transformations and replacing the largest outliers of the log transformations with the inner fence (Hamilton 1991).

Health insurance coverage categories are mutually exclusive. Beneficiaries who had Medicaid coverage (dual-eligibility) for the entire year are categorized under Medicaid regardless of the presence of other coverage. Medicaid enrollment was ascertained from the administrative files. For the remaining beneficiaries, the self-reported type of the secondary insurance was used to determine whether the person was enrolled in an employer-sponsored insurance plan (ESI), received benefits from a capitation plan known as Medicare Advantage plans rather than the traditional Medicare (HMO), remained in the traditional plan but purchased additional supplemental coverage known as Medigap plans (private), or remained in the traditional plan with no other supplemental insurance (FFS). Insurance coverage rates were calculated as

$$
1 \text { - (OOP spending/spending by all payers) }
$$


and rates were presented in percentages.

\section{Analyses}

The statistical significance of bivariate associations between 2005 and 2010 were tested by Wilcoxon rank-sum tests when the outcome variable was highly skewed; otherwise, $t$ statistics were calculated for continuous variables and chi-square statistics were calculated for categorical variables (e.g., self-rated health by year). For the multivariate analyses, we estimated generalized linear models with a gamma distribution and logarithmic link function modeling economic burden of health care (or its components); explanatory variables were demographics and socioeconomic conditions, self-rated health, and the insurance plans that cover the beneficiary. We report the average marginal effect of all covariates. The MCBS sample is stratified by age; the oldest old (ages 85 and older) were oversampled. Samples are drawn within zip codes designated as primary sampling units. The results we present are weighted, except for the sample sizes and Wilcoxon rank-sum test. Calculation of the standard errors took the complex survey design into account.

\section{Results}

In 2010, median out-of-pocket health care spending as a share of income was 12 percent (Table 1). One in four beneficiaries spent at least 20 percent of their income for health care; one in 10 beneficiaries spent more than 32 percent of their income for. When these numbers were compared with the pre-reform levels (2005), differences were mainly observed on the right tail of the distributions, suggesting that the changes were mostly beneficial to those who were spending a substantial part of their income on health care. For example, the top 5 percent were spending 51 percent or more of their income on health care in 2005; the $95^{\text {th }}$ percentile of the distribution was down to 42 percent in 2010. However, the bivariate differences across the periods did not reach statistical significance $(p=0.067)$.

When out-of-pocket spending is decomposed into premiums, health services, and prescription drugs, we observed statistically and substantially different rates when we compared 2010 to 2005. A substantial change was observed in out-of-pocket spending for prescription drugs: In 2010, median spending was 1.3 percent of income, down from 1.9 percent in 2005 (a 32 percent decline), accompanied by an increase in insurance coverage rates for prescription 
drug services. Premiums (as a share of income) have increased for most of the beneficiaries ( $p<$ 0.001), except for the top decile. Out-of-pocket spending for health services as a share of income was statistically equivalent between 2005 and 2010 ( $p=0.508)$, with some substantial declines observed for the top decile. Insurance coverage rate for health services remained unchanged as well. Within the out-of-pocket spending for health care, the share of prescription drugs decreased and the share of premiums increased.

The burden of health care costs was associated with the presence and type of supplemental insurance. Medicaid beneficiaries bear the lowest levels of burden (3.4 percent), even though their annual incomes are the lowest and their anticipated health needs may be the highest (suggested by percentage reporting fair/poor health). Those who supplement traditional Medicare with Medigap bear the highest levels of burden, spending 15.2 percent of their income on health care, even though their incomes were relatively higher than many others. When duals are excluded, the subgroup with the lowest income and worse self-rated health received traditional Medicare coverage without any supplement, spending 12 percent of their income on health care. Those who had ESI or those who were enrolled in managed care spent approximately 11 percent of their income on health care.

The changes from 2005 to 2010 were more pronounced in two subgroups, defined by the presence and type of supplemental insurance plan (Table 2). Traditional fee-for-service Medicare enrollees, with or without a Medigap supplement, experienced the largest gains. For example, for the group with Medigap supplement, we observed a sharp decline in the economic burden for prescription drugs (from 2.6 to 1.6, along with an increased drug coverage rate), also driving down the overall burden of health care. However, these results should be interpreted with caution: The population who chose to stay with the traditional plan declined-and differences may be driven by the selection into the group, which itself is likely to be affected by income. Our results suggest that more people have enrolled in managed care plans during the period under consideration.

The size of the population with ESI was smaller in 2010 (8.5 million), compared with 2005 (9.9 million). This group had the largest median income (\$32,400), and spent 11.1 percent of their income on health care (approximately 72 percent of their spending on health care was for health insurance premiums). One pattern was uniform for all subgroups, when 2010 was 
compared with 2005: Of the amount they spent on health care, every subgroup shifted some spending from prescription drugs to premiums.

When the bivariate analyses were stratified by income quintiles, we observed stronger and robust temporal statistical associations within the lowest quintile (Table 3) but not in the others. The economic burden of prescription drugs declined for all, and as expected, the declines were sharper for the lower-income groups. The economic burden of premiums has increased significantly for the $2^{\text {nd }}, 3^{\text {rd }}$, and $4^{\text {th }}$ quintiles; the lowest-income group was protected from a significant increase. The highest-income beneficiaries were spending more on premiums than other health care expenses, even in 2005, which may be a reason their burden of premiums has not increased significantly. In the bivariate calculations, the net effect was only significant for the lowest-income group, with overall burden of health care declining from 22.3 percent to 17.9 percent (25 percent decline). Premium and copayment subsidies were highly aligned with the income of the beneficiary. Consequently, the effects were most pronounced in the lowest quintile.

While bivariate analyses shed some light on the changes between 2005 and 2010, a careful analysis needs to control for the underlying changes in demographic, health status, and socioeconomic changes as well, particularly income between the two cross sections. Income has various direct effects (denominator of the measure) and indirect effects (affordability on insurance coverage, utilization) on economic burden of health care. Given that many health service utilization events are necessities (e.g., emergency room use for cardiac events), and others have low-income elasticity (e.g., care for severe acute events), it is expected that people with lower incomes spend a larger share of their income on health care. The variations in the economic burden of health care once income levels are controlled for are of concern, indicating vulnerabilities to (or protection from) financial strain, beyond consumer preferences. In addition, the economic burden variables are highly skewed, thus, limiting the analyses to central tendencies (e.g., Table 2) may bias the true gains from 2005 to 2010. Therefore, we estimated multivariate generalized linear models with gamma distribution and log link function (Table 4) to isolate the differences in economic burden between years 2005 and 2010, net of demographic, health status, and socioeconomic changes, particularly income, using pooled data from 2005 and 2010. Presented coefficients are the average marginal effects of the year dummy (2010), estimated from the regression models where the dependent variable is regressed upon year, 
gender, age, race, education, income quintiles, and self-rated health, using the pooled data from 2005 and 2010.

Comparing 2010 to 2005, the decline in overall burden of health care was 1.4 percentage points, and reached statistical significance, net of demographic, health status, and socioeconomic differences. When the components of out-of pocket health care spending were examined, we observed that beneficiaries spent 1.3 percentage points less for prescription drugs, and 0.5 percentage points less for medical services. The coefficient for premium spending indicated an increase over the period, but the difference did not reach statistical significance, suggesting it did not offset the gains from prescription drugs and medical spending.

When subgroups defined by the presence and type of supplemental insurance were examined separately, we observed that every subgroup experienced a decline in the burden of prescription drugs, but at varying sizes: around 2 percentage points for duals, traditional Medicare enrollees with and without a Medigap supplement; less than1 percentage point for managed-care enrollees or those who had coverage sponsored by an employer. The economic burden of inpatient and outpatient health services declined or remained flat for all. While duals, managed care and Medigap enrollees experienced negligible increases in premiums, those with no supplement experienced a 1.6 percent increase in premiums (although this coefficient did not reach statistical significance, perhaps because of the small number of people who remained in this group in 2010), and those with ESI experienced a 1.4 percent increase in premiums. As a result of all these factors, dual eligibles and Medigap enrollees had significant reductions in the share of income spent on health care (2.7 and 2.4 percentage points respectively), HMO beneficiaries and those who remain in traditional plan without a supplement experienced some reduction, but neither reached statistical significance in the conventional levels $(p<0.05)$, and ESI beneficiaries experienced no net gains, suggesting that the savings from prescription drugs were offset by additional spending on premiums.

\section{Discussion}

At the fifth year of Medicare Part D program implementation, we observed that Medicare beneficiaries, particularly those targeted by the program (e.g., the poor, those who are not equipped with employer-sponsored insurance plans) experienced a substantially lower economic burden of prescription drugs (defined as out-of-pocket spending as a share of annual income). 
The trend was accompanied by a lower economic burden of inpatient/outpatient services. Some increase in the premiums was observed as well, but it was not large enough to offset these gains. As a result, the economic burden of out-of-pocket spending on health care, including premiums, has declined during the period (2005 compared to 2010). Reforms substantially benefited those who had catastrophic expenses (relative to their income), suggested by the $75^{\text {th }}, 90^{\text {th }}$ and $95^{\text {th }}$ percentiles of the burden distributions. Medicaid continued its role as a safety net for those who are most vulnerable to financial strain. The burden of health care costs for people with dual coverage declined substantially, suggesting that premium- and cost-sharing assistance for beneficiaries with low incomes was making changes in the intended direction.

Even with these gains, however, health care costs continued to be major economic burden for the elderly in the year 2010. Median out-of-pocket health care spending as a share of income was 12 percent; one in four beneficiaries spent at least 20 percent, and one in 10 beneficiaries spent more than 32 percent of their income on health care. One in 10 beneficiaries spent more than 20 percent of their income on insurance premiums. These numbers, as expected, are consistently lower than estimates for populations that include the non-elderly disabled and elderly in institutional care and when cost of institutional and dental care are taken into consideration. For example, in 2006, the median economic burden for all services and premiums for the entire Medicare population was 16 percent; 19 percent of this spending was for institutional care and 6 percent was for dental care (Neuman, Cubanski, Desmond, et al. 2007). However, because the focus of the current study is to isolate the effect of the reforms (as much as it can be within the limitations of data available in the MCBS) on measures that are most likely to be affected by improved access to prescription drugs, we limited the scope to premiums, inpatient/outpatient services, and prescriptions.

Improved coverage for prescription drugs was associated with a reduced economic burden of inpatient and outpatient services, indirectly adding to the body of literature on the effects of the skin in the care, i.e., the cost sharing, particularly aiming to reduce over use of health care by the consumer (Neuman, Cubanski, Desmond, et al. 2007; and Neuman, Cubanski, and Damico 2009). It has been shown that increasing copayments for outpatient care raised health care costs for elderly Medicare enrollees through adverse health events (Trivedi, Moloo, and Mor 2010). Another study showed that increased co-payments for physician visits and prescription drugs were accompanied by increased spending for inpatient care: For every dollar 
saved on doctor and drug spending, Medicare’s hospital spending increased by more than $\$ 6$ (Chandra, Gruber, and McKnight 2010). Earlier studies examining the effects of Part D on shorter terms (one to two years) showed minor or no reductions in spending for medical services, but reductions were significant in our study, as we extended the follow-up to five years (Kaestner and Khan 2010; and Zhang, Donohue, Lave, et al. 2009).

An important social concern is the economic security of the "near-poor"-beneficiaries who have too much income or too many assets to qualify for public assistance, yet are still quite needy economically (Shea, Stuart, and Briesacher 2003). For this segment of the Medicare population, supplemental insurance coverage represents a tradeoff between insurance and other expenses, such as food and shelter. Our analyses stratified by income quintiles revealed that the gains were most pronounced with the lowest quintile, as expected, since premium and copayment subsidies were highly aligned with the income of the beneficiary. In 2010, beneficiaries in the second income quintile spent less on prescription drugs, compared with what their counterparts were spending in 2005. However, they spent more for premiums—enough to offset the gains. Current policy debates include a provision to increase Medicare Part B and D premiums for some higher-income beneficiaries (Cubanski and Neuman 2015). This may help to finance an expansion of premium subsidies to help the near-poor.

The trends regarding those who possess employer-sponsored benefits may be of concern. In 2010, fewer people fit our inclusion criteria (elderly, continuously enrolled, and living in the community for the entire year) and also received employer-sponsored benefits, compared with 2005. Moreover, they experienced the sharpest increases in premiums. These observations are parallel to the trends for the working non-elderly in the United States: they are paying more but getting fewer protective benefits (Collins, Radley, Schoen, et al. 2014; and Schoen, Radley, and Collins 2015).

Premium and coinsurance subsidies are important tools to relieve the high economic burden of health care. Innovations to help elderly enrollees make the best use of their health care dollars, such as cost calculators that help them understand where they are in their deductible level, as well as transparency in price and coinsurance of alternative therapeutics can also be effective tools (Delbanco 2013). Some health plans have been developing transparency tools, but their dissemination among the elderly is challenging because many of them have limitations in literacy and numeracy (Hanoch, Rice, Cummings, et al. 2009; and Rice, Hanoch, and 
Cummings 2010). For the elderly, the best use of dollars allocated for premiums has been a daunting task (Jacobson, Swoope, Perrym and Slosar 2014); many of them did not want to switch plans because the process of their initial plan selection was so frustrating. Tools that make it easier for beneficiaries to compare and switch plans when it is in their interest to do so would help alleviate the economic burden of health care.

These findings should be interpreted with caution, given the limitations of the current study. The purchase of supplemental and prescription drug insurance coverage is voluntary, constrained by income, price, and the availability of plans and also represents preferences and risk aversion. Selection into various levels and types of insurance coverage is also influenced by health care needs and expected utilization, particularly for chronic conditions. Causal interpretations are further limited by the repeated cross-section design. MCBS measures included flowing income but no assets, thus underestimating the economic means of the beneficiaries. In addition, our income adjustment for married couples may be overestimating their purchasing power. Our scope is limited to premiums, spending for prescription drugs, and spending for inpatient and outpatient services, excluding spending on institutional and home health care and dental. At the same time, focusing on these three components is a unique contribution of the current study and allowed us to delineate the effect of a major change in prescription drug coverage. External validity and the richness of expenditure measures in the MCBS strengthen our study.

America's top health care priority continues to be the affordability of high-cost drugs for the management of chronic conditions. Proposals to secure Medicare will continue to include adjustments to premiums, as well as cost sharing for health services and prescription drugs. We showed some relief in the economic burden of health care in the fifth year of the implementation of Part D, particularly for those who were most vulnerable to financial strain. Still, given the size and the unequal distribution of the economic burden of health care, we conclude that the economic burden needs to be a continuous concern when policy alternatives are discussed. 


\section{References}

Chandra, A., J. Gruber, and R. McKnight. 2010 "Patient Cost-Sharing and Hospitalization Offsets in the Elderly." American Economic Review 100(1): 193-213.

Collins, S. R., D. C. Radley, C. Schoen, et al. 2014. "National Trends in the Cost of Employer Health Insurance Coverage, 2003-2013." Issue Brief. New York, NY: The Commonwealth Fund.

Collins, S. R. P. W. Rasmussen, S. Beutel, and M. M. Doty. 2015. "The Problem of Underinsurance and How Rising Deductibles Will Make It Worse." Issue Brief. New York, NY: The Commonwealth Fund.

Crystal, S., R. W. Johnson, J. Harman, et al. 2000. "Out-of-Pocket Health Care Costs Among Older Americans." The Journals of Gerontology Series B: Psychological Sciences and Social Sciences 55(1): S51-62.

Cubanski, J. and T. Neuman. 2015. "Medicare's Income-Related Premiums: A Data Note." Data Note. Menlo Park, CA: The Henry J. Kaiser Family Foundation.

Desmond, K. A., T. H. Rice, J. Cubanski, et al. 2007. "The Burden of Out-of Pocket Health Spending Among Older Versus Younger Adults: Analysis from the Consumer Expenditure Survey, 1998-2003." Medicare Issue in Brief. Menlo Park, CA: The Henry J. Kaiser Family Foundation.

Delbanco, S. 2013. "Price Transparency Tools: The Good News, the Challenges, and the Way Forward." Health Affairs Blog. Washington, DC: Health Affairs. Available at: http://healthaffairs.org/blog/2013/11/20/price-transparency-tools-the-good-news-thechallenges-and-the-way-forward/

Duggan, M. and F. S. Morton. 2008. "The Effect of Medicare Part D on Pharmaceutical Prices and Utilization." Working Paper 13917. Cambridge, MA: National Bureau of Economic Reseach.

Fronstin, P., D. Salisbury, and J. VanDerhei. 2012. "Savings Needed for Health Expenses for People Eligible for Medicare: Some Rare Good News." EBRI Notes 33(10): 1-7.

Goldman, D. P. and J. M. Zissimopoulos. 2003. "High Out-of-Pocket Health Care Spending by the Elderly." Health Affairs 22(3): 194-202.

Jacobson, G., C. Swoope, M. Perry, and M. C. Slosar. 2014. "How Are Seniors Choosing and Changing Health Insurance Plans? Findings from Focus Groups with Medicare Beneficiaries." Report. Menlo Park, CA: Kaiser Family Foundation.

Hamilton, L. C. 1991. "Resistant Normality Check and Outlier Identification. Reprinted in Stata Technical Bulletin Reprints." Stata Press 3(1): 86-90. 
Hanoch, Y., T. Rice, J. Cummings, et al. 2009. "How Much Choice Is Too Much? The Case of the Medicare Prescription Drug Benefit." Health Services Research Journal 44(4): 11571168.

Ingber, M. J., S. Freeman, D. Healy, et al. 2011. "Medicare Part D Program Evaluation: Analysis of the Impact of Medicare Part D on the FFS Program and Issues Related to Medication Adherence for Six Chronic Conditions - 2008." Final Report. Research Triangle Park, NC: RTI International.

Kaestner, R. and N. Khan. 2010. "Medicare Part D and Its Effect on the Use of Prescription Drugs, Use of Other Health Care Services and Health of the Elderly." Working Paper 16011. Cambridge, MA: National Bureau of Economic Research.

Madden, J. M., A. J. Graves, F. Zhang, et al. 2008. "Cost-Related Medication Nonadherence and Spending on Basic Needs Following Implementation of Medicare Part D." Journal of the American Medical Association 299(16): 1922-1928.

Neuman, T., J. Cubanski, K. A. Desmond, et al. 2007. "How Much 'Skin in the Game' Do Medicare Beneficiaries Have? The Increasing Financial Burden of Health Care Spending, 1997-2003." Health Affairs 26(6): 1692-1701.

Neuman, T., J. Cubanski, and A. Damico. 2009. "Revisiting 'Skin in the Game’ Among Medicare Beneficiaries, an Updated Analysis of the Increasing Financial Burden of Health Care Spending from 1997 to 2005." Data Spotlight. Menlo Park, CA: The Henry J. Kaiser Family Foundation.

Pottow, J. A. E. 2011. "The Rise in Elder Bankruptcy Filings and the Failure of U.S. Bankruptcy Law." The Elder Law Journal 19(1): 119-158.

Rice. T., Y. Hanoch, and J. Cummings. 2010. "What Factors Influence Seniors' Desire for Choice Among Health Insurance Options? Survey Results on the Medicare Prescription Drug Benefit." Health Economics, Policy and Law 5(4): 437-457.

Schneeweiss, S., A. R. Patrick, A. Pedan, et al. 2009. "The Effect of Medicare Part D Coverage on Drug Use and Cost Sharing Among Seniors without Prior Drug Benefits." Health Affairs 28(2): w305-316.

Schoen, C., D. C. Radley, and S. R. Collins. 2015. "State Trends in the Cost of Employer Health Insurance Coverage, 2003-2013." Issue Brief. New York, NY: The Commonwealth Fund.

Shea, D., B.C. Stuart, and B. A. Briesacher. 2003. "Caught in Between: Prescription Drug Coverage of Medicare Beneficiaries Near Poverty." Issue Brief. New York, NY: The Commonwealth Fund.

The Henry J. Kaiser Family Foundation. 2014. "The Medicare Part D Prescription Drug Benefit." Fact Sheet. Menlo Park, CA. 
Trivedi, A. N., H. Moloo, and V. Mor. 2010. "Increased Ambulatory Care Copayments and Hospitalizations Among the Elderly." The New England Journal of Medicine 362(4): 320-328.

U. S. Census Bureau. 2015. Poverty Thresholds. Washington, DC.

Zhang, J. X., W. Yin, S. X. Sun, et al. 2008. "The Impact of the Medicare Part D Prescription Benefit on Generic Drug Use." The Journal of General Internal Medicine 23(10): 16731678.

Zhang, Y., J. M. Donohue, J. R. Lave, et al. 2009. "The Effect of Medicare Part D on Drug and Medical Spending." The New England Journal of Medicine 361(1): 52-61.

Zissimopoulos, J., G. F. Joyce, L. M. Scarpati, et al. 2015. "Did Medicare Part D Reduce Disparities?" The American Journal of Managed Care 21(2): 119-128. 
Table 1. Economic Burden of Health Care and Its Components

\begin{tabular}{|c|c|c|c|}
\hline & 2005 & 2010 & Equality test \\
\hline $\begin{array}{l}\text { Spending on health care (premiums and out-of-pocket } \\
\text { spending for health services and Rx) as a share of } \\
\text { income ( percent) }\end{array}$ & & & 0.067 \\
\hline Median & 11.8 & 11.6 & \\
\hline $75^{\text {th }}$ percentile & 21.3 & 19.7 & \\
\hline $90^{\text {th }}$ percentile & 35.4 & 31.6 & \\
\hline $95^{\text {th }}$ percentile & 50.6 & 42.2 & \\
\hline Premium spending as a share of income ( percent) & & & 0.001 \\
\hline Median & 7.0 & 7.6 & \\
\hline $75^{\text {th }}$ percentile & 12.3 & $\overline{13.0}$ & \\
\hline $90^{\text {th }}$ percentile & 21.0 & 20.9 & \\
\hline $95^{\text {th }}$ percentile & 28.8 & 27.9 & \\
\hline $\begin{array}{l}\text { Out-of-pocket spending for health services as a share } \\
\text { of income ( percent) }{ }^{\text {a }}\end{array}$ & & & 0.508 \\
\hline Median & 0.8 & 0.8 & \\
\hline $75^{\text {th }}$ percentile & 2.7 & 2.5 & \\
\hline $90^{\text {th }}$ percentile & 8.7 & 7.0 & \\
\hline $95^{\text {th }}$ percentile & 17.4 & 13.0 & \\
\hline $\begin{array}{l}\text { Out-of-pocket spending for prescription drugs as a } \\
\text { share of income ( percent) }\end{array}$ & & & 0.001 \\
\hline Median & 1.88 & 1.32 & \\
\hline $75^{\text {th }}$ percentile & 4.52 & 2.95 & \\
\hline $90^{\text {th }}$ percentile & 9.46 & 5.87 & \\
\hline $95^{\text {th }}$ percentile & 14.69 & 8.60 & \\
\hline \multicolumn{4}{|l|}{ Median of insurance coverage rate ( percent) for } \\
\hline Health Services & 91.4 & 89.4 & 0.001 \\
\hline $\mathrm{Rx}$ & 69.0 & 74.1 & 0.001 \\
\hline \multicolumn{4}{|l|}{$\begin{array}{l}\text { Distribution of Out-of-pocket spending on health care } \\
\text { (percent) }^{b}\end{array}$} \\
\hline Premiums & 60.6 & 66.3 & 0.001 \\
\hline Medical & 16.2 & 15.5 & 0.095 \\
\hline $\mathrm{Rx}$ & 23.3 & 18.2 & 0.001 \\
\hline
\end{tabular}

Note: Equality test column represents the $p$ value for the $z$ statistic testing the equality of the distributions, based on Two-sample Wilcoxon rank-sum (Mann-Whitney) test, except for distribution of spending. a: cost sharing for inpatient, outpatient and medical provider services, excluding prescription drugs. b: distribution is calculated for each beneficiary and reported numbers are averages of beneficiaries' share. Equality test is based on $t$-test. 
Table 2. Economic Burden of Health Care, and Its Components, Stratified by Supplemental Insurance

\begin{tabular}{|c|c|c|c|c|c|c|c|c|c|c|c|c|c|c|c|}
\hline & \multicolumn{3}{|c|}{ Medicaid } & \multicolumn{3}{|c|}{ None (FFS only) } & \multicolumn{3}{|c|}{ HMO } & \multicolumn{3}{|c|}{ ESI } & \multicolumn{3}{|c|}{ Private } \\
\hline & 2005 & 2010 & & 2005 & 2010 & & 2005 & 2010 & & 2005 & 2010 & & 2005 & 2010 & \\
\hline \multicolumn{16}{|l|}{$\begin{array}{l}\text { Median pending as a } \\
\text { share of income for }\end{array}$} \\
\hline Health care (total) & 3.8 & 3.4 & & 13.8 & 12.0 & $*$ & 11.0 & 10.8 & & 10.0 & 11.1 & * & 16.5 & 15.2 & $*$ \\
\hline Premiums & 0.0 & 0.0 & $\mathrm{a}$ & 6.6 & 7.3 & $*$ & 6.8 & 7.2 & $*$ & 5.9 & 7.4 & * & 10.7 & 11.0 & \\
\hline Health Services & 0.3 & 0.7 & $*$ & 2.3 & 1.7 & & 0.6 & 0.7 & $*$ & 0.9 & 0.9 & & 0.9 & 0.8 & \\
\hline $\mathrm{Rx}$ & 1.4 & 1.3 & & 2.1 & 1.1 & $*$ & 1.9 & 1.4 & * & 1.5 & 1.0 & * & 2.6 & 1.6 & $*$ \\
\hline \multicolumn{16}{|l|}{$\begin{array}{l}\text { Median insurance } \\
\text { coverage rate ( } \\
\text { percent) for }\end{array}$} \\
\hline Health Services & 99.0 & 97.0 & * & 73.1 & 72.0 & & 87.6 & 81.5 & * & 91.2 & 90.0 & * & 93.3 & 93.0 & \\
\hline $\mathrm{Rx}$ & 93.6 & 95.5 & $*$ & 38.8 & 71.3 & $*$ & 60.8 & 70.5 & $*$ & 79.0 & 80.0 & * & 39.6 & 65.3 & * \\
\hline \multicolumn{16}{|l|}{$\begin{array}{l}\text { Distribution of } \\
\text { spending on health } \\
\text { care ( percent) }\end{array}$} \\
\hline Premiums & 7.2 & 11.1 & * & 55.0 & 63.3 & $*$ & 66.8 & 69.4 & $*$ & 64.4 & 72.0 & * & 68.6 & 74.8 & $*$ \\
\hline Medical & 32.8 & 35.6 & & 25.3 & 23.2 & & 12.0 & 12.9 & $*$ & 16.7 & 15.2 & $*$ & 11.1 & 11.1 & \\
\hline $\mathrm{Rx}$ & 60.0 & 53.2 & $*$ & 19.7 & 13.5 & * & 21.2 & 17.7 & $*$ & 18.9 & 12.8 & $*$ & 20.2 & 14.2 & $*$ \\
\hline Income (in $\$ 1,000$ ) & 8.8 & 9.9 & * & 13.3 & 18.0 & $*$ & 19.8 & 24.0 & $*$ & 27.6 & 32.4 & * & 23.8 & 28.0 & $*$ \\
\hline $\begin{array}{l}\text { percent with } \\
\text { fair/poor health (b) }\end{array}$ & 40.8 & 36.6 & & 25.5 & 21.9 & & 18.7 & 18.8 & & 15.4 & 14.2 & & 16.0 & 14.7 & \\
\hline $\begin{array}{l}\text { Size (weighted, in } \\
\text { million beneficiaries) }\end{array}$ & 2.7 & 2.8 & & 2.4 & 1.8 & & 4.3 & 9.5 & & 9.9 & 8.5 & & 10.0 & 9.3 & \\
\hline
\end{tabular}

${ }^{*} \mathrm{p}<0.05$ for the $z$ statistic testing the equality of the distributions, based on Two-sample Wilcoxon rank-sum (Mann-Whitney) test.

a: while not reflected in the medians because mode is 0 , the distributions are statistically significantly different $(\mathrm{p}<0.05)$.

b: test comparing 2005 to 2010 rates are based on chi-square statistic. 
Table 3. Economic Burden of Health Care, and Its Components, Stratified by Income Quintiles

\begin{tabular}{|c|c|c|c|c|c|c|c|c|c|c|c|c|c|c|c|}
\hline \multirow{3}{*}{$\begin{array}{l}\text { Median pending as } \\
\text { share of income for }\end{array}$} & \multicolumn{3}{|c|}{ Lowest } & \multicolumn{3}{|c|}{ 2nd } & \multicolumn{3}{|c|}{ 3rd } & \multicolumn{3}{|c|}{ 4th } & \multicolumn{3}{|c|}{ Highest } \\
\hline & 2005 & 2010 & & 2005 & 2010 & & 2005 & 2010 & & 2005 & 2010 & & 2005 & 2010 & \\
\hline & & & & & & & & & & & & & & & \\
\hline Health care (total) & 22.3 & 17.9 & $*$ & 18.3 & 18.9 & & 13.3 & 12.9 & & 9.8 & 10.0 & & 5.7 & 5.5 & \\
\hline Premiums & 10.6 & 11.1 & & 9.5 & 11.8 & $*$ & 7.7 & 8.3 & $*$ & 6.3 & 6.7 & $*$ & 3.5 & 3.7 & \\
\hline Health Services & 1.6 & 1.5 & & 1.2 & 1.4 & & 1.0 & 0.9 & & 0.7 & 0.7 & & 0.5 & 0.4 & \\
\hline $\mathrm{Rx}$ & 3.6 & 2.0 & * & 3.2 & 2.1 & $*$ & 2.3 & 1.4 & * & 1.5 & 1.2 & $*$ & 0.8 & 0.6 & * \\
\hline $\begin{array}{l}\text { Median insurance } \\
\text { coverage rate } \\
\text { (percent) for }\end{array}$ & & & & & & & & & & & & & & & \\
\hline Health Services & 94.2 & 93.4 & * & 91.7 & 88.7 & $*$ & 91.2 & 88.4 & * & 90.8 & 88.8 & $*$ & 89.5 & 87.8 & * \\
\hline $\mathrm{Rx}$ & 76.7 & 88.8 & * & 66.7 & 74.0 & $*$ & 66.0 & 71.9 & * & 68.1 & 70.0 & $*$ & 68.2 & 71.2 & * \\
\hline $\begin{array}{l}\text { Distribution of } \\
\text { spending on health } \\
\text { care ( percent) }\end{array}$ & & & & & & & & & & & & & & & \\
\hline Premiums & 44.9 & 47.9 & * & 59.6 & 68.9 & * & 64.2 & 71.5 & * & 66.5 & 71.1 & $*$ & 67.1 & 71.5 & * \\
\hline Medical & 21.4 & 22.4 & & 16.6 & 14.6 & & 14.6 & 13.1 & & 13.9 & 13.5 & & 14.8 & 14.2 & \\
\hline $\mathrm{Rx}$ & 33.7 & 29.6 & * & 23.8 & 16.5 & $*$ & 21.2 & 15.5 & * & 19.6 & 15.4 & $*$ & 18.2 & 14.3 & * \\
\hline
\end{tabular}

${ }^{*} \mathrm{p}<0.05$ for the $z$ statistic testing the equality of the distributions, based on Two-sample Wilcoxon rank-sum (Mann-Whitney) test.

b: test comparing 2005 to 2010 rates are based on chi-square statistic. 
Table 4: Period Effect on Economic Burden of Health Care, and Its Components, Overall and Stratified by Supplemental Insurance

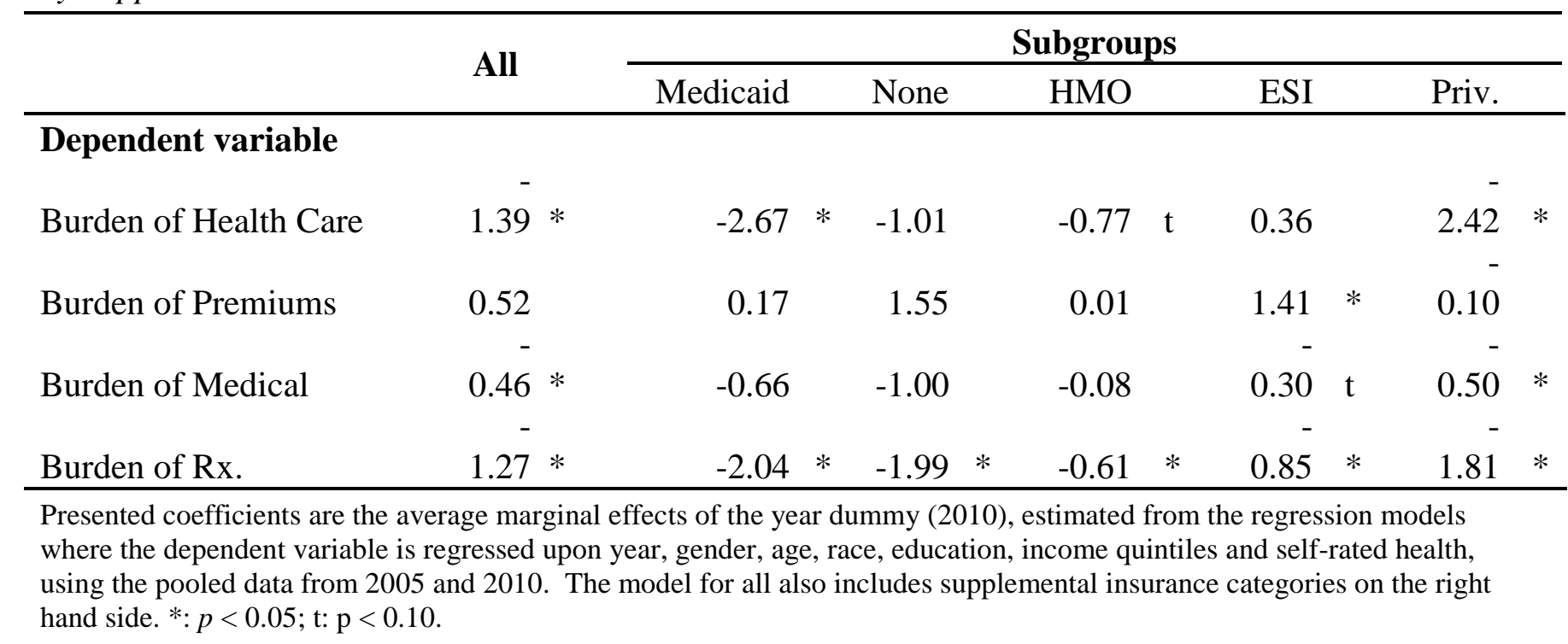




\begin{tabular}{|c|c|c|}
\hline & 2005 & 2010 \\
\hline All & 7,936 & 7,032 \\
\hline \multicolumn{3}{|l|}{ Gender } \\
\hline Male & 2,005 & 2,010 \\
\hline Female & 4,548 & 4,025 \\
\hline \multicolumn{3}{|l|}{ Race } \\
\hline White & 2,005 & 2,010 \\
\hline Black & 666 & 595 \\
\hline Hispanic/Other Race & 372 & 343 \\
\hline \multicolumn{3}{|l|}{ Age } \\
\hline $65-74$ & 2,005 & 2,010 \\
\hline $75-84$ & 3,206 & 2,792 \\
\hline $85+$ & 1,560 & 1,484 \\
\hline \multicolumn{3}{|l|}{ Education } \\
\hline$<$ High School & 2,005 & 2,010 \\
\hline High School Graduate & 4,286 & 3,914 \\
\hline Some College or Higher & 1,389 & 1,419 \\
\hline \multicolumn{3}{|l|}{ Income Quintiles $^{\mathbf{a}}$} \\
\hline Lowest 20 percent & 2,005 & 2,010 \\
\hline $2^{\text {nd }}$ & 1,654 & 1,489 \\
\hline $3^{\text {rd }}$ & 1,582 & 1,432 \\
\hline $4^{\text {th }}$ & 1,579 & 1,316 \\
\hline Highest 20 percent & 1,444 & 1,254 \\
\hline \multicolumn{3}{|l|}{ General Health } \\
\hline Excellent-Good & 2,005 & 2,010 \\
\hline General Health is Fair-Poor & 1,582 & 1,343 \\
\hline \multicolumn{3}{|l|}{ Supplemental Insurance } \\
\hline Medicaid & 2,005 & 2,010 \\
\hline None (Medicare fee-for-service only) & 650 & 388 \\
\hline Medicare HMO & 1,159 & 2,087 \\
\hline Employer-sponsored Insurance (ESI) & 2,648 & 1,871 \\
\hline Private Self-Purchased & 2,699 & 1,981 \\
\hline
\end{tabular}




\section{RECENT WORKING PAPERS FROM THE CENTER FOR RETIREMENT RESEARCH AT BOSTON COLLEGE}

The Impact of Temporary Assistance Programs on the Social Security Claiming Age Geoffrey T. Sanzenbacher, April Yanyuan Wu, and Matthew S. Rutledge, October 2015

Do Households Increase Their Savings When the Kids Leave Home? Irena Dushi, Alicia H. Munnell, Geoffrey T. Sanzenbacher, and Anthony Webb, September 2015

Evaluating the Impact of Social Security Benefits on Health Outcomes Among the Elderly Padmaja Ayyagari, September 2015

Does Age-Related Decline in Ability Correspond with Retirement Age? Anek Belbase, Geoffrey T. Sanzenbacher, and Christopher M. Gillis, September 2015

Job Polarization and Labor Market Outcomes for Older, Middle-Skilled Workers Matthew S. Rutledge and Qi Guan, September 2015

What Causes Workers to Retire Before They Plan? Alicia H. Munnell, Geoffrey T. Sanzenbacher, and Matthew S. Rutledge, September 2015

Calculating Neutral Increases in Retirement Age by Socioeconomic Status Geoffrey T. Sanzenbacher, Anthony Webb, Candace M. Cosgrove, and Natalia S. Orlova, August 2015

How Does Occupational Access for Older Workers Differ by Education?

Matthew S. Rutledge, Steven A. Sass, and Jorge D. Ramos-Mercado, August 2015

How Much Longer Do People Need to Work?

Alicia H. Munnell, Anthony Webb, and Anqi Chen, August 2015

The Challenge of Pension Reform in Georgia: Non-Contributory Pensions and Elderly Poverty

Tamila Nutsubidze and Khatuna Nutsubidze, July 2015

The Transition from Defined Benefit to Defined Contribution Pensions: Does It Influence Elderly Poverty?

Natalia S. Orlova, Matthew S. Rutledge, and April Yanyuan Wu, July 2015

Will the Average Retirement Age Continue to Increase?

Matthew S. Rutledge, Christopher M. Gillis, and Anthony Webb, July 2015

All working papers are available on the Center for Retirement Research website (http://crr.bc.edu) and can be requested by e-mail (crr@bc.edu) or phone (617-552-1762). 